\title{
Microstructure, composition of quartz in carbonate veins from the gold deposits in the Jiaodong Peninsula, China
}

\author{
LI HONGYAN ${ }^{1}$, WANG DONG ${ }^{1}$, WANG TIANQI ${ }^{1,2}$, \\ $\mathrm{YU} \mathrm{HONG}^{1}$ \\ ${ }^{1}$ Institute of Mineral Resources, CAGS, Beijing 100037, \\ China, e-mail: hylicags @126.com \\ ${ }^{2}$ Institute of Geology and Geophysics, CAS, Beijing 100029, \\ China
}

Advantages have been shown to study rock-forming or ore-forming process by combining microstructure with in-situ element and isotope geochemistry of minerals. The Jiaodong Peninsula, eastern China, has long been a hotspot of geological study for its gigantic scale of gold product. Though, origin of the deposits is controversial. We present new data of SEM+CL, EPMA and LA-ICPMS for quartz, siderite and calcite to discuss the genesis of gold deposits.

In the Jiaodong Peninsula and many other metallogenic provinces, carbonization and quartz-carbonate alteration were commonly regarded as indication the end of mineralization. Our study shows that carbonate veins occur in many gold deposits. 3 stages of siderite vein during mineralization process have been identified in Dayingezhuang gold deposit, a representative deposit in the Jiaodong Peninsula. Quartz in the first stage of siderite vein show a core-rim structure, magmatic and hydrothermal CL features can be observed in the core and the rim, respectively. Quartz in the second stage is euhedral, retaining hexagonal pseudoform of hightemperature quartz, and has hydrothermal CL feature. The quartz in the third stage present fine-grained aggregate with hydrothermal CL feature.

Combining with the study of fluid inclusions and C-O isotopes of quartz and carbonate minerals, we propose that the ore-forming fluid experienced a process of evolution from high-temperature magmatic melt/fluid in the early stage to low-temperature hydrothermal fluid in the late stage. Abundant evidences already indicate that lithospheric mantle in the eastern part of the North China Craton experienced carbonatitic melt metasomatism, and the strongest metasomatism region is spatially consistent with the Jiaodong Peninsula. Therefore, the carbonate melt/fluids closely related to the mineralization of gold in the area are probably products of partial melting of metasomatized mantle.

*This study is supported by the fund from the Ministry of Science and Technology of People's Republic of China (2016YFC0600105) and the National Natural Science Foundation of China (41673058 and 4152098). 